Como una contribución a la investigación del movimiento obrero y de la clase empresarial en la República Dominicana presentamos un registro de los comunicados publicados por las principales organizaciones sindicales del país y las principales organizaciones empresariales, y en algunos casos también se incluyen empresas particulares. El registro abarca el período correspondiente al primer gobierno del Partido Revolucionario Dominicano del 16 de agosto de 1978 al 16 de mayo de 1982. Creemos que los comunicados contribuyen a descifrar la dinámica de la clase obrera y la burguesía dominicana tanto en sus relaciones mutuas como en su relación con el Estado. En este sentido, los comunicados constituyen un dato valioso para el investigador social que se proponga el estudio del movimiento obrero y empresarial y de los conflictos que han caracterizado la sociedad dominicana en el período sefialado.

El registro se basa en los comunicados obreros publicados en el periódico El Sol y los comunicados empresariales publicados en el periódico Listín Diario. La metodología utilizada consiste en indicar en la columna de la izquierda la fecha de 
publicación del periódico (día, mes y año) y la página en que aparece el comunicado; y en la columna de la derecha el nombre de las(s) organización(es) firmante(s) seguido de un breve resumen del contenido de la(s) temática(s) principal(es) del comunicado.

Ejemplo:

25-6-81:9

UGTD, CGT, CASC, CNTD,
CUT.

Rechazan cancelaciones masivas en empresas del Estado.

Siglas utilizadas:

AIRD: Asociación de Industrias de la República Dominicana. AIRD-RN: Asociación de Industrias de la República DominicanaRegión Norte.

ACIS: Asociación de Comerciantes e Industriales de Santiago. AEIH: Asociación de Empresas Industriales de Herrera. ADHA: Asociación Dominicana de Hacendados y Agricultores. ADP: Asociación Dominicana de Profesores.

CNHE: Consejo Nacional de Hombres de Empresa.

CPRD: Confederación Patronal de la República Dominicana.

COCAI-DN: Cámara Oficial de Comercio, Agricultura e Industria del Distrito Nacional.

COCAI-Stgo: Cámara Oficial de Comercio, Agricultura e Industria de Santiago.

CGT: Central General de Trabajadores.

CNUS: Consejo Nacional de la Unidad Sindical.

CIS: Comité Intersindical de Solidaridad.

CNTD: Confederación Nacional de Trabajadores Dominicanos.

CASC: Confederación Autónoma de Sindicatos Clasistas.

CUT: Central Unitaria de Trabajadores.

CEA: Consejo Estatal del Azúcar.

CDA: Compañía Dominicana de Aviación.

CDE: Corporación Dominicana de Electricidad.

FENSA: Federación Nacional de Sindicatos Azucareros.

FENTICOMMC: Federación Nacional de Trabajadores de la Industria de la Construcción, Madera y Materiales de Construcción.

FENATRADO: Federación Nacional de Transporte Dominicano. FENATRATER: Federación Nacional de Transporte Terrestre. 
INESPRE: Instituto de Estabilización de Precios. MSUO: Movimiento Sindical de la Unidad Obrera. ONATRATE: Oficina Nacional de Transporte Terrestre.

OIT: Organización Internacional del Trabajo.

SNTT: Sindicato Nacional de Trabajadores Telefónicos.

SET: Secretaría de Estado de Trabajo.

SITRACOMEDO: Sindicato de Trabajadores del Complejo Metalúrgico Dominicano.

SITRACODE: Sindicato de Trabajadores de la Corporación Domininicana de Electricidad.

SUTRAFADO: Sindicato Unido de Trabajadores de la Falconbridge Dominicana.

SITRARODOM: Sindicato de Trabajadores de la Rosario Dominicana.

SITRACAASD: Sindicato de Trabajadores de la Corporación de Acueductos y Alcantarillados de Santo Domingo.

SITRAINDRHI: Sindicato de Trabajadores del Instituto Dominicano de Recursos Hidráulicos.

UGTD: Unión General de Trabajadores Dominicanos.

UNACHOSIN: Unión Nacional de Choferes Sindicalizados.

\section{COMUNICADOS OBREROS}

Fuente: El Sol.

18-8-78:13 Sindicato de Trabajadores de la Compañía Dominicana de Alimentos Lácteos (Sitracodal).

Saludo al nuevo gobierno. Denuncia de abusos sindicales cometidos por la empresa, en particular el despido de dirigentes sindicales, en violación de la libertad sindical. Solicitan intervención del Secretario de Trabajo.

23-8-78:23 Sindicato Libre de Trabajadores de la Gulf + Western Corporation.

Desmienten desafiliación de miembros que declarara la CGT y la acusan de divisionista.

26-8-78:13 Sindicato Libre de Trabajadores de la Gulf + Western Corporation.

Defensa del sindicato ante acusaciones de otras 
organizaciones obreras. Señalan que dentro de la austeridad obtuvieron cuantiosas conquistas, lo que no lograron otras organizaciones sindicales.

31-8-78:5 CGT.

Denuncia de abusos cometidos desde la inauguración del gobierno del PRD contra la libertad sindical en numerosas empresas del país, a pesar de la promesa del nuevo gobierno de respetar las leyes, la Constitución y la libertad de Asociación. Piden comisión de la OIT para que se investiguen abusos e irrespeto a la libertad sindical.

31-8-78:28 Unión Sindical de Trabajadores Portuarios de las Márgenes Oriental y Occidental del Río Haina.

Denuncian acciones para crear sindicato amarilloColorado.

1-9-78:3 Sindicato de Trabajadores de Pinturas Dominicanas.

Protestan por cancelaciones de empleados. Critican contrato de la empresa con Corripio.

5-9-78:23 Sindicato Unido Autónomo Portuario, Arrimo y Profesional.

Acusan sindicatos que operan en la margen occidental del río Haina de haberse adueñado de los trabajos por su relación con el anterior gobierno. Rechazan acusaciones de ser colorado siendo el caso lo contrario.

11-9-78:22 Sindicato Unido de Trabajadores del Central Romana.

Denuncia y comunica a la clase obrera las maniobras de la empresa para cambiarle el nombre al Sindicato Libre y usar el de Sindicato Unido.

12-9-78:21 Sindicato Nacional de Trabajadores Telefónicos (SNTT).

Critican y rechazan solicitud del gobierno de tregua laboral. 
14-9-78:3 Sindicato de Trabajadores de METALDOM.

Denuncian cancelaciones por intentar formar un sindicato en la empresa y otras violaciones sindicales.

18-9-78:21 CGT.

Se opone a tregua laboral que perjudique a la clase trabajadora. Se denuncian violaciones a la libertad sindical. Se rechaza la creación de una central vinculada al PRD.

19-9-78:16 Federación Nacional de Transporte Dominicano (FENATRADO).

Conflicto camioneros con INESPRE. Rechazan denuncias de que detrás del conflicto se ocultan fines políticos para crear problemas al gobierno.

11-10-78:24 Sindicato de Trabajadores de Pinturas Dominicanas.

Denuncian que la administración no quiere reconocer el sindicato.

12-10-78:25 Trabajadores de PIDOCA.

Rechazan acusación del sindicato a la administración y defienden la gestión de la administración.

21-10-78:13 CGT.

La Asamblea Consultiva resuelve rechazar la austeridad y la tregua laboral, la creación de una central amarilla de orientación perredeísta y la represión sindical.

25-10-78:3 Miembros del Comité Unificado para la Reorganización del Sindicato Unido del Central Romana.

Rechazan intentos de miembros de orientación perredeísta de celebrar asambleas y elegir delegados al margen del comité. Demandan intervención de las autoridades de la Secretaría de Trabajo.

1-11-78:5 Sindicato de Trabajadores de la Industria del Cemento. 
Rechazan despidos de obreros perredeístas que son sustituidos por otros perredeístas con más influencia dentro de los mecanismos y estructuras del PRD o fracciones del partido.

2-11-78:13 Sindicato Autónomo de Trabajadores del Ingenio Montellano.

Rechazan acusaciones de la CASC a través de su Federación de Trabajadores de la Caña (Fentraca) y ratifican su desafiliación de esa organización y su afiliación a la CGT. Acusan a la CASC de haber apoyado el régimen de Balaguer y de haber usado el nombre del sindicato para apoyar candidaturas partidarias como la de F. Alvarez Bogaert.

3-11-78:19 Sitracode, SNTT, Sutrafado, y el Sindicato de Trabajadores de Talleres Cima.

Rechazan intento del PRD de crear una central sindical. Lo consideran divisionista.

11-11-78:5 Comité Unitario para la Reorganización del Sindicato del Central Romana.

Exponen al Secretario de Trabajo violación del acuerdo de unidad suscrito por parte de los dirigentes de la fracción del PRD quienes realizaron elecciones ilegales. Piden respeto a acuerdo unitario.

16-12-78:13 Sindicato Unido de Trabajadores de la Falconbridge Dominicana (Sutrafado).

Exponen problemas con la empresa en el pago de bonificaciones de 1977, pago de horas extras, etc. Critican al gobierno por no cumplir con el programa del PRD.

13-2-79:21 Sindicato Nacional de Trabajadores del Instituto Dominicano de Recursos Hidráulicos (Sinatraindrhi).

Denuncia represión sindical y cancelaciones.

14-2-79:25 Sindicato Unido de Trabajadores del Ingenio Porvenir. 
Solicitan a la empresa se le condone deuda de tiempo muerto dadas las dificultades económicas que confrontan los trabajadores.

2-3-79:3 CGT y un conjunto de sindicatos afiliados a esa Central.

Repudian intento de la Gulf y la UGTD de tratar de destruir el derecho de los trabajadores del Central para organizarse con independencia del patrón y del gobierno. Solicitan a la SET que no se registre como legal el intento de elecciones puesto en práctica por la Gulf y la UGTD a espaldas de miles de trabajadores del Central Romana, y que intervenga en defensa de la libertad sindical.

6-3-79:3 Sindicatos de Trabajadores de la Editora El País.

En solidaridad con los trabajadores de Color Visión para que se reponga a su secretario general y se discuta pacto colectivo.

27-3-79:5 Comité Intersindical de Solidaridad (CIS), SNTT, Sitracode, Sutrafado, Sitracomedo, Sitrataci, ADP.

Rechazan agresión de Falconbridge contra trabajadores que luchan por el pago de bonificaciones atrasadas y la firma de un pacto colectivo. Exigen reposición de cancelados.

27-3-79:5 Sutrafado.

Protesta por cancelación de dirigentes sindicales ante anuncio de huelga. Exigen reposición.

3-4-79:27 Sutrafado.

Deciden paro de 24 horas en demanda reposición de cancelados. Que se forme comisión mediadora.

11-4-79:4 CNTD, MSUO, CGT, FENTICOMMC, Fenatrater, Fenatrado, SNTT, Sindicato de Trabajadores de la Sociedad Industrial Manicera, POASI, Sindicato de Trabajadores de la Rosario Dominicana, Sindicato de Trabajadores de Productos Diversos. 
Condenan aumento precio gasolina y derivados del petróleo. Declaran insuficiente aumento de salarios. Exigen que el gobierno absorba aumentos del combustible con la eliminación de los intermediarios y la nacionalización de la refinería.

12-4-79:9 Comité Intersindical de Solidaridad (CIS).

Llamado a celebración unitaria del 10 de mayo.

18-4-79:38 CGT, CASC, CNTD, MSUO, FENTICOMMC, FENTRATER.

Acuerdo celebración 1으 de mayo unitario. UGTD anuncia su próxima integración. Llamado a unidad.

19-4-79:22 Comité Intersindical de Solidaridad (CIS).

Otros sindicatos se integran a llamado unitario para la celebración del 10 de mayo unitario.

23-4-79:5 CGT (y organizaciones afiliadas).

Apoyo lucha maestros. Llamado unitario con motivo celebración 1 으 de mayo.

28-4-79:8 Comité Intersindical de Solidaridad (CIS).

Conflictos obreros en La Vega.

28-4-79:29 Sutrafado.

Denuncia sobre despido de obreros repuestos después de la huelga en demanda de pago de bonificaciones y firma pacto colectivo.

1-5-79:29 CASC (y organizaciones afiliadas).

Manifiesto con motivo celebración 1으 de mayo.

8-5-79:9 Sindicato Nacional de Trabajadores de Empresas Televisoras y Afines.

Denuncia sobre violación de libertad sindical en Color Visión, cancelación de dirigentes sindicales y rechazo firma pacto colectivo. 
11-5-79:7 Sindicato Autónomo del Ingenio Montellano.

Protesta por decisión del Senado de excluir del salario mínimo de 125 pesos sometido por el Poder Ejecutivo a los trabajadores de la caña y de zonas francas.

14-5-79:4 Federación de Trabajadores de la Caña (Fentraca).

Protesta por decisión del Senado de excluir del aumento de salario mínimo a los trabajadores de la caña y de zona franca.

15-5-79:4 CGT (y organizaciones afiliadas).

Protesta por exclusión del aumento de salario mínimo de los trabajadores azucareros, de zonas francas, tabaqueros y de empresas con déficits sugerida por el Senado. Protesta por congelamiento de salarios por dos años. Demandan salarios mínimos más altos.

16-5-79:4 Sindicato de Trabajadores Algodoneros del Inda, Sindicato Sacos y Tejidos Dominicanos-Textil Los Mina.

Denuncia de cancelaciones y manejo administrativo inadecuado en varias empresas estatales.

11-6-79:4 Sindicato Nacional de Manejadores de Instrumentos Topográficos.

Exige se establezca nueva tarifa de salario mínimo.

11-6-79:19 Sindicato de Trabajadores de la Corporación Dominicana de Electricidad (Sitracode).

Conflictos firma pacto colectivo. Rechazan acusaciones de la empresa de prácticas desestabilizadoras y reafirman apego a la ley.

12-6-79:5 Sindicato de Trabajadores del Complejo Metalúrgico Dominicano (Sitracomedo).

Exponen actitud intransigente de la empresa al discutirse reajustes salariales y pacto colectivo.

4-7-79:13 Ocho sindicatos del Ingenio Río Haina. 
Denuncian negativa de la empresa para discutir pacto colectivo. Dan plazo para negociaciones.

24-7-79:18 Sindicato Dueños de Camiones de Volteo.

Respaldo al Sindicato Unido del Central Romana en negociaciones estancadas con la Gulf + Western.

1-8-79:4 Unión Nacional de Choferes Sindicalizados (Unacho$\sin )$.

Informan sobre promesas reivindicativas ofrecidas por el Presidente de la República en reunión celebrada con dirigentes choferiles.

3-8-79:4 Sitracomedo.

Denuncian despido sindicalistas en Metaldom. Responsabilizan patronos de acción y exigen reposición cancelados.

3-8-79:8 Comité de Lucha Choferil, Federación Nacional de Transporte Terrestre.

Anuncian fines reivindicativos del paro choferil y su terminación en 48 horas. Exigen reducción precio combustible.

3-8-79:27 Varios sindicatos de Santiago.

Hacen llamado a que se adopte actitud sensata ante hechos ocurridos por aumento precio combustibles y paros choferiles. Apoyan diálogo con el Presidente de la República.

6-8-79:3 Sindicato de Trabajadores de la Rosario Dominicana. Exigen reposición cancelados en Metaldom.

13-8-79:4 Sindicato de Trabajadores de la Editora El País. Solidaridad con los trabajadores de Metaldom. Rechazan acusaciones de la empresa de que el movimiento huelguístico es partidario y comunista.

15-8-79:7 CGT (y organizaciones afiliadas). 
A un año del 'cambio' lucha contra las medidas antiobreras. Que se nacionalice el oro, la refinería y otras empresas extranjeras para enfrentar la crisis económica y que no se le cargue al pueblo como se ha hecho. Reajustes de salarios de acuerdo al costo de la vida. Libertad sindical y respeto derechos democráticos. Apoyo lucha Metaldom, reposición cancelados y negociación pacto colectivo. Llamado unitario a todas las centrales en lucha por reivindicaciones y respeto derechos democráticos.

15-8-79:13 Sitrarodom.

Exponen proceso democrático en que se realizaron las elecciones de directiva sin interferencia de los empresarios ni de organizaciones obreras oportunistas.

17-8-79:4 Sitracomedo.

Se propone a Metaldom reposición dirigentes cancelados, respeto a los obreros que han participado en la huelga, ejercicio democracia sindical, continuación discusión pacto colectivo y retiro fuerzas policiales de la empresa, como condición para levantar la huelga.

30-8-79:6 Sindicato de Trabajadores de la Corporación de Acueductos y Alcantarillado de Santo Domingo.

Exponen filosofía del sindicato a nuevos directivos de la Corporación.

8-9-79:26 CGT, CASC, UGTD, CNTD, MSUO, FENTICOMMC, CIS, FENSA.

Acuerdan construir Comité Sindical de Reconstrucción Nacional a raíz del huracán David.

27-9-79:18 Federación Nacional de Sindicatos Azucareros (Fensa).

Rechazan intento golpe de Estado a pesar de que el gobierno no representa las aspiraciones de la clase obrera. 
5-10-79:7 Sindicato Autónomo de Obreros y Empleados de la Industria Nacional del Vidrio.

Alertan al Presidente de la República sobre aprobación del directorio del desarrollo industrial de una fábrica de vidrio en la ciudad de Santiago.

5-10-79:30 Unachosin.

Respaldan gobierno y PRD ante intento golpe de Estado $\mathrm{y}$ actividades desestabilizadoras.

11-10-79:4 Sitracode.

Conflicto sobre seguridad en que laboran los obreros.

19-10-79:9 Sindicato Unido de Trabajadores del Central Romana.

Denuncian actitud negativa de la Gulf + Western en negociación firma pacto colectivo. Piden mediación directa del Secretario de Trabajo.

19-10-79:32 Sitrarodom.

Satisfacción por nacionalización de la Rosario Dominicana. Que se garantice la permanencia en los puestos de trabajo y respeto al pacto colectivo.

23-10-79:4 Sindicato Autónomo de Trabajadores de Sacos y Tejidos Dominicanos.

Inicio de lucha por pacto colectivo hace reaparecer ola represión y cancelaciones en Textil Los Mina.

29-10-79:6 Sitracaasd.

Denuncian cancelaciones injustas de técnicos y dirigentes sindicales por participar en comisión negociadora de pacto colectivo.

30-10-79:4 Varios sindicatos afiliados a la CGT.

Denuncian violaciones que se cometen en el Hostal Nicolás de Ovando contra los obreros, como atraso en el pago de salarios e incumplimiento del pago del seguro social. 
1-11-79:20 Sitracaasd.

Refuta director sobre declaraciones explicando motivo cancelaciones.

6-11-79:4 Sutrafado.

Denuncian dilación de la empresa en estudio sobre propuesta de pacto colectivo. Disposición de luchar contra arbitrariedades.

6-11-79:29 Sitracaasd. (Firman también: CGT, UGTD, MSUO, FENTICOMMC, FENSA, SNTV, CIS, CASC).

Denuncian cancelaciones de 5 técnicos y 2 dirigentes sindicales en momentos de calma laboral cuando las negociaciones del pacto colectivo se encontraban suspendidas desde la llegada del nuevo director. Demandan reposición inmediata de cancelados y firma del pacto colectivo. Solidaridad con el sindicato del Hostal Nicolás de Ovando.

6-11-79:10 Sutrafado.

La Iglesia Unida de Canadá vende acciones Falconbridge porque considera inapropiada la actuación de la empresa en el área de la responsabilidad social.

10-11-79:7 Sindicato de Trabajadores de Leche Fresca.

Defiende calidad productos de la empresa ante acusaciones.

14-11-79:18 Tres sindicatos del Ingenio Porvenir.

Exponen preocupación porque el CEA no ha hecho aún ningún pronunciamiento sobre las bonificaciones. Exponen precariedad económica de los obreros de la caña.

22-11-79:17 Sindicato Autónomo de Trabajadores del Ingenio Monte Llano.

Exigen bonificaciones y pago completo de regalía pascual. Deploran pronunciamiento Presidente Guzmán de que no se autoriza a otorgar bonificaciones porque el CEA enfrenta una crisis económica. 
22-11-79:35 Doce sindicatos del CEA.

Exponen preocupación porque el CEA aún no ha declarado ganancias ni su intención de otorgar bonificaciones. Llamado a la unidad de todos los trabajadores de ingenios del CEA para formar comités de lucha para reclamar bonificaciones, reajustes salariales, el respeto a la libertad sindical y la firma de pactos colectivos ya que la mayoría tienen años vencidos. Que la Gulf + Western pague los 38 millones que adeuda al gobierno dominicano.

24-11-79:6 Sindicato Unido de Trabajadores de la Cervecería Vegana (Sitracerve).

Denuncian violación libertad sindical por cancelación de participantes en elecciones sindicales. Solicitan la mediación del Secretario de Trabajo.

28-11-79:33 Treinta y seis organizaciones sindicales de Ingenios azucareros.

En asamblea donde participaron más de 39 organizaciones sindicales, especialmente de los ingenios estatales, se acordó solicitar entrevista al Presidente de la República para tratarle: que se entregue bonificación 1978-79, un reajuste general de salarios, que se dé cumplimiento a la ley 45 que establece el salario mínimo en 125 pesos, que se agilice en el CEA el proceso de negociación de pactos colectivos, que se garantice la libertad sindical y la reposición de cancelados, y que se dé un mes de regalía pascual a los trabajadores temporeros.

1-12-79:4 Varias organizaciones laborales del norte y noroeste (predominan sindicatos afiliados a la CGT).

Solicitan reposición de sindicalistas cancelados en la Cervecería Vegana.

1-12-79:10 Sitracaasd.

Carta pública al Congreso y a la Secretaría de Trabajo donde se exponen argumentos legales que avalan la defensa de los cancelados y que muestran actos de violación a la libertad sindical. 
13-12-79:23 Federación Nacional de Trabajadores de la Alimentación, Dulces y Bebidas (Fenatradube). De la CGT.

Solidaridad con los trabajadores de la Codal y Pepsi-Cola que discuten pactos colectivos con ambas multinacionales. Denuncian patronos mantienen actitud negativa. Solidaridad con los trabajadores azucareros que luchan por el pago de bonificaciones.

15-12-79:26 UGTD.

Saludan firma pacto colectivo en el Central Romana, lo que demuestra que el sindicato no era amarillo como se ha sugerido. Observan cuidadosamente los grupos en el Comité Sindical Azucarero para que la lucha reivindicativa no se utilice con fines políticos.

15-12-79:26 Organizaciones sindicales del Ingenio Boca Chica.

Reafirman voluntad de luchar por bonificación, regalía, reajuste salarial, pacto colectivo y reposición de dirigentes cancelados.

11-1-80:11 Sitracaasd.

Libertad sindical y que cese represión sindical en la CAASD. Exigen reposición cancelados.

12-1-80:9 Comité Nacional Coordinador Azucarero. (Firman delegados de las centrales CGT, UGTD, CASC y representantes de ingenios).

Sobre puntos reivindicativos sólo se ha llegado a acuerdo sobre calendario para la discusión de pactos colectivos. Llamado para que no se recurra a tácticas dilatorias.

14-1-80:7 CGT (Comisión Nacional del Area Azucarera).

Critican funcionamiento del Comité Nacional Azucarero que vacila en la defensa de las reivindicaciones obreras. Llamado a que se tomen medidas más efectivas en la lucha por las bonificaciones, aumento salarios y firma pactos colectivos en los ingenios. 
16-1-80:7 Federación Nacional de Trabajadores.

Apoyo lucha obrera en Nestlé por firma pacto colectivo. Empresa usa represión y tácticas dilatorias. Solidaridad con los trabajadores de PepsiCola en su lucha por la firma de pacto colectivo, y con los obreros cañeros por su bonificación.

16-1-80:8 Sitracode.

En aniversario nacionalización de la CDE demandan resto derechos trabajadores.

22-1-80:5 Comité Nacional Coordinador Azucarero.

Después de acordarse la calendarización discusión pactos colectivos no se han resuelto otros puntos demandados y el CEA ha pospuesto reuniones indefinidamente. Demandan bono, firma inmediata pactos colectivos, aplicación ley 45 de salario mínimo, reposición cancelados y libertad sindical. Plazo de 72 horas para que el CEA satisfaga demandas.

\section{4-1-80:5 CGT.}

En respeto decisión asamblea, los ingenios serán paralizados por 24 horas si el CEA no satisface demandas. Rechazan mediación UGTD o cualquier otra que no sea la Secretaría de Trabajo.

\section{5-1-80:9 CGT.}

Constancia de no haber firmado acuerdo que la mayoría del Comité Nacional Coordinador Azucarero firmó en que el CEA concede sólo 15 días de bonificación que descontará de beneficios futuros. El comité se negó a convocar pleno por temor a que las masas rechacen propuesta del CEA. Condenan método anti-democrático de una parte del Comité, y la actitud asumida por la UGTD y la CAASD que propusieron que las organizaciones que no firmaran se sacaran del acuerdo. Con la actitud adoptada por la mayoría del Comité Coordinador la unidad del movimiento se rompe, lo que imposibilita que los trabajadores triunfen en su reclamo original. 
26-1-80:8 CGT.

Bono de 30 días, préstamo no. Ante la posición de las otras centrales que aceptan préstamo propuesto por el CEA, la CGT resuelve: mantener invariable demandas, respaldar paro por resolución de la asamblea. Condenan acciones represivas en algunos ingenios, y de continuarse se extenderá paro.

30-1-80:21 Sutrafado.

Crítica a dirigente CGT quien junto a dirigente del Sitrarodom impidieron la unidad y conformación de la Federación Minero-metalúrgica al oponerse a la participación del Sindicato de Talleres Cima.

30-1-80:25 Sindicatos del Ingenio Río Haina.

Repudio cancelaciones en la empresa.

7-2-80:27 Bloque de Sindicatos del Ingenio Río Haina.

Invitan a asamblea para analizar situación azucareros y programar plan de lucha para reposición cancelados en el CEA.

3-2-80:11 Varias organizaciones sindicales del Cibao.

Piden sustitución director del CEA y reposición cancelados, discusión pactos colectivos y entrega bonificaciones. Solución a la crisis de los trabajadores del Tabaco en Tamboril, intervención del Secretario de Trabajo en conflicto Codal ante negativa para firmar pacto colectivo. Reforma agraria como prioridad nacional.

9-4-80:7 Sindicato de Trabajadores de la Editora El País.

Solidaridad con los trabajadores azucareros. Que se repongan más de 1,500 cancelados en lucha por bonificación.

5-5-80:23 Sindicato Autónomo de Trabajadores del Ingenio Montellano.

Se ha violado pacto colectivo al cancelar dirigentes protegidos por la inamovilidad sindical. Acusan 
administración de no cumplir con las leyes $y$ de convertirse en activista de la UGTD.

20-5-80:7 Sindicato Nacional de Trabajadores de Empresas Televisoras y Afines.

Se afilia a la CGT.

30-5-80:11 CGT.

Los trabajadores no deben pagar la crisis petrolera con aumentos en el precio de los artículos. Es necesario coordinar una respuesta de todos los trabajadores. Se dará inicio a movimientos destinados a recuperar el poder de compra de los salarios. Disposición de colaborar con otras organizaciones que estén en disposición de luchar por estas reivindicaciones.

2-6-80:34 Unachosin, Siuchodisna, Comisión Asesora de la UGTD.

Ante alza insensible de la gasolina: que se rebaje la gasolina a los choferes hasta que se busque medida definitiva al transporte, que se revise decreto que crea Onatrate para que se dé representación a los sindicatos más representativos.

2-6-80:21 Sitracodal.

Rechazo comisión laudo arbitral.

2-6-80:6 Movimiento Independiente de Choferes (MICHO).

En demanda de que se baje el precio de la gasolina, cese represión, continúe el subsidio a los choferes, y que el Presidente se reúna con los choferes.

4-6-80:7 SNTT.

Denuncian represión en Codetel y violación pacto colectivo. Rechazo medidas gobierno ante crisis del petróleo.

4-6-80:9 CGT, CASC, MSUO, Sitrarodom, Sitrasid, Amucaba, Anpa.

Apoyo huelga choferes en rechazo alza desmedida de la gasolina, y por la incapacidad del gobierno para 
resolver las más elementales necesidades de los sectores populares. Aprueban programa común: rechazo medidas del gobierno que afectan poder de compra, reajuste permanente de salarios, promulgación nuevo código de trabajo, pago subsidio choferes, reposición cancelados en el CEA y CORDE, nacionalización y eliminación privilegios de empresas extranjeras multinacionales, moratoria deuda externa. Se anuncia inicio formación de un organismo representativo del movimiento sindical que se denominará Comité $\mathrm{Na}$ cional de Unidad Sindical (CNUS) para impulsar la unidad de acción.

7-6-80:12 Sindicato Autónomo de Industrias Asociadas.

Denuncian medidas represivas de la empresa y negativa a diálogo con dirigentes sindicales para discutir problemas obrero-patronales.

12-6-80:7 Sindicato Unido de Choferes Nacionales.

Suspenden huelga acogiendo propuesta de la CGT para dar tiempo a entrevista con el Presidente de la República por parte de Siuchodisna y el CNUS. Reafirman carácter reivindicativo y no político del movimiento. Que se deje sin efecto aumento gasolina a 54 centavos, que se paguen subsidios atrasados, se nacionalice la refinería, etc.

12-6-80:5 Comisión Consultiva Pro-Fundación del CNUS.

Ante crisis económica, actitud anti-obrera de los patronos y limitaciones a la libertad sindical se impulsa movimiento sindical a la unidad de acción.

6-7-80:27 Sindicato de Trabajadores de Sacos y Tejidos Dominicanos.

Nuevamente Textil Los Mina se atrasa en el pago de salarios sin que se conozcan motivos.

30-7-80:7 Sindicatos de Trabajadores de Taller y Reparaciones de Vehículos.

Denuncian violación libertad sindical ante cancelaciones dirigentes directos después de formarse sindicato. 
31-7-80:3 Sitracode.

Denuncian trama destruir sindicato. Apoyo unidad de acción del movimiento obrero en el CNUS.

31-7-80:5 Comisión Consultiva Pro-Fundación del CNUS. Solidaridad con lucha de maestros y la ADP.

1-8-80:9 Sindicatos Hato Nuevo, CEA.

Demandan cumplimiento pacto colectivo. Solidaridad con la ADP y los trabajadores de Leche Fresca.

5-8-80:11 Sitracode.

Denuncian violaciones que se cometen contra el sindicato y el pacto colectivo.

7-8-80:11 Sindicato de Trabajadores de la Editora El País. Exigen reposición maestros.

7-8-80:17 Sindicato Autónomo de Trabajadores de Molinos Dominicanos.

Solicitan al Presidente Guzmán sustitución del administrador quien viola pacto colectivo.

9-8-80:19 Sutrafado.

En acto solidaridad con maestros la policía interrumpe y atropella participantes.

12-8-80:7 Sindicato de Trabajadores de la Editora El País.

Solidaridad con el pueblo haitiano.

15-8-80:18 Comisión Consultiva Pro-Fundación del CNUS.

Conjunto de demandas obreras ante hecho represivos y anti-obreros.

22-8-80:12 Sitrarodom.

Niega acusaciones de la UGTD y el MPD de malversación de fondos contra el secretario general. Acusan la UGTD de ser central amarilla. Conflicto surge en torno a la Federación de Trabajadores Mineros y Metalúrgicos. 
25-8-80:33 Sindicato Unido del Central Romana.

Apoya acción gobierno por recuperar 38 millones que la Gulf + Western adeuda.

25-8-80:42 Sutrafado.

Rechazan acusación de Sitrarodom contra el secretario general.

28-8-80:21 Sitracode.

Asamblea somete al Presidente de la República una terna para elegir representante laboral en el consejo directivo. Se otorga poder a la directiva para que se decida sobre afiliación del CNUS. Condena represión sindical y exige libertad sindical en el CDE.

30-8-80:6 Comité Gestor Pro-Reestructuración del Sindicato Fraternal del Ingenio Montellano.

Acusan CGT de anarquista e izquierdizante. Llamado a trabajadores para que no se identifiquen con la CGT.

4-9-80:26 CGT.

Aclaración sobre distorsiones acerca de las elecciones en el ingenio Montellano y conflicto al respecto con la UGTD.

11-9-80:17 Sindicato de Trabajadores de la CDA (Sitracoda).

En lucha por mejores condiciones de trabajo.

12-9-80:13 Bloque de Sindicatos del Ingenio Río Haina.

Que se les entregue la parte que les corresponde de los 38 millones que adeuda la Gulf + Western.

18-9-80:24 Sindicato de Trabajadores de Industria Lavador.

Denuncia cancelaciones y planes de la empresa de destruir el sindicato.

25-9-80:17 Varios sindicatos del Ingenio Porvenir.

Exponen situación económica del CEA. Demandan que el Senado apruebe préstamo para el CEA. 


\section{2-10-80:5 Sitrarodom.}

En medio de acciones represivas-sindicales a nivel nacional se advierte contra cualquier medida que en su contra pueda cometer la empresa en su lucha porque se paguen horas de comida que se les adeuda.

14-10-80:23 Sindicato Unido del Central Romana.

Explican situación en que se expulsó grupo delegados que tenían fines divisionistas y difamaban directivos.

15-10-80:25 Sitrarodom.

Apoyo lucha maestros. Contra cancelaciones en la Falconbridge. Demandan intervención del gobierno en conflicto Leche Fresca.

3-11-80:10 SNTT.

Denuncia cancelaciones en Codetel con el fin de no discutir el pacto colectivo pendiente. Exigen reposición cancelados y firma pacto colectivo. Por un CNUS fuerte.

4-11-80:9 Sutrafado.

Exponen falsedad argumento Falconbridge de alargar paro de operaciones en base a supuesta crisis internacional del níquel.

6-11-80:7 CGT (y organizaciones afiliadas).

Que el Presidente de la República escuche y dialogue con los maestros.

8-11-80:31 Bloque de Sindicatos del Ingenio Río Haina.

Reclaman bonificaciones.

12-11-80:9 Sitracode.

Denuncian violaciones del pacto colectivo. Repudio represión patronal en Codetel, la Manisera, Envases Antillanos, Falconbridge.Por el fortalecimiento del CNUS. 
14-11-80:7 Sitrarodom.

Denuncian golpeo patronal y del gobierno al movimiento sindical.

19-11-80:4 Federación de Empleados de Telecomunicaciones y Correos.

Repudio agresión Codetel y la policía contra el SNTT cuando demandaban reposición cancelados y nuevo pacto colectivo.

22-11-80:23 UGTD, Bloque de Sindicatos Azucareros.

En representación de más de un $70 \%$ de los trabajadores del CEA se reclaman 45 días de bonificación y condonación del préstamo de la bonificación pasada, cumplimiento y firma de los pactos colectivos en los ingenios Quisqueya, Porvenir, Boca Chica, Amistad y Esperanza.

24-11-80:11 CGT.

Resoluciones del 5to. Pleno Nacional. Movilización para enfrentar el deterioro del nivel de vida.

25-11-80:9 Bloque de Sindicatos del Ingenio Río Haina.

Denuncian medidas anti-obreras del CEA de no pagar bonificaciones y dar un préstamo de un mes, lo que ha propuesto FENSA.

4-12-80:5 Varios Sindicatos Azucareros.

Ante posición del CEA de no dar bonificaciones aludiendo pérdidas se exige que el préstamo se extienda a los obreros agrícolas, que se repongan cancelados por lucha bonificación, que el préstamo no sea descontado de las liquidaciones de prestaciones legales sino de futuras bonificaciones, que se revisen los pactos colectivos y se firmen donde no hay.

4-12-80:29 Unachosin.

Demandan plan de grupo ligado al gobierno (a la tendencia del Presidente Guzmán) de desprestigiar dirección. 
9-12-80:4 CGT.

Apoyo al Sinatraindrhi, reposición cancelados, pago del mes de noviembre y libertad sindical.

9-12-80:20 Federación Nacional de Transporte y sus Afines.

Rechazan acusaciones de Unachosin.

7-1-81:9 Bloque Sindicatos de la Industria Cementera Nacional.

Piden al gobierno que en los aumentos del precio del cemento se incluyan 5 centavos por funda destinados a la construcción de viviendas para los trabajadores.

17-1-81:3 Sindicatos del Ingenio Barahona.

Se oponen intención grupo PRD de que se realicen cancelaciones $\vee$ se destituya al administrador.

22-1-81:10 Sindicato Autónomo de Trabajadores de Productos Diversos.

Denuncian acciones anti-sindicales de la empresa y cancelación de directivos. Llamado a la CGT quien ha aceptado diálogo con el CNHE para que comprenda la imposibilidad del mismo dadas las acciones represivas de los patronos.

28-1-81:5 Sitrarodom.

Solicitan se les pague dinero adeudado por tiempo almuerzo.

28-1-81:5 Unachosin - Comité Cibao.

Piden al gobierno cumplir promesas hechas el 4 de junio de 1980 a raíz de la última huelga de transporte.

2-2-81:37 Sitrarodom.

Niegan argumento de la empresa de que no hay deuda pendiente por horas de trabajo. 
4-2-81:7 Sitracodal.

Denuncian cancelación dirigentes. Incumplimiento laudo arbitral en lucha por pacto colectivo.

12-2-81:7 Sutrafado.

Denuncian negativa de la empresa de tomar posición sobre ley de bonificaciones. Solidaridad con varios grupos laborales en lucha.

5-3-81:17 Sindicato Unido de Trabajadores de la Cervecería Vegana.

Denuncian ola de cancelaciones. Se ha violado acuerdo de no despedir dirigentes sindicales. Solidaridad con trabajadores de la Codal, Tamara, y Textil Los Mina.

6-3-81:5 SNTT.

Denuncia Codetel dilación por neqociación pacto colectivo argumentando crisis económica. Apoyo luchas obreras.

7-3-81:9 FENTICOMMC (y otras 36 organizaciones sindicales). Rechazan impugnación que hace Cerámica del Caribe sobre resolución 181 que fija salario mínimo para albañiles.

11-3-81:5 Sitrarodom.

Solicitan al Presidente de la República tener representante en el consejo directivo.

11-3-81:19 CGT, Fenatradube, Sitracodal.

Denuncian desconocimiento Codal del pacto colectivo, despido dirigentes sindicales, planes de destruir sindicato y caso omiso a la SET.

12-3-81:22 Sindicato de Trabajadores Nabisco-Tamara

Rechazan reiteración de la empresa a la SET de que no podrán discutir con el sindicato cláusulas pendientes del pacto colectivo por crisis económica. Piden se discuta pacto. 
12-3-81:25 Sindicato Nacional de Trabajadores de la Compañía Embotelladora (Pepsi-Cola) .

Denuncian cancelación dirigentes sindicales, intenciones de destruir sindicato y negativa a otorgar bonificaciones por falta de ganancias.

12-3-81:29 Bloque Sindical del Ingenio Río Haina.

Incumplimiento cláusulas del pacto colectivo por parte de la empresa.

13-3-81:9 Fenatrado.

Contra los intentos de desplazamiento del INESPRE. Anuncian paro.

18-3-81:9 CGT.

Contra la represión sindical de la Nestlé-Codal. Cancelan dirigentes y violan laudo arbitral. Llamado a piquete.

20-3-81:19 Sindicato Nacional de Trabajadores de la PepsiCola.

Que la SET ejerza mediación efectiva en conflicto Denuncian acciones anti-sindicales.

26-3-81:7 CGT.

Apoyo lucha médicos.

28-3-81:21 Sindicato de Trabajadores de Nabisco-Tamara.

Esta multinacional continúa desconociendo fuero sindical al despedir obrero en violación al pacto colectivo. Los despidos se han agudizado desde la demanda por la negociación de las cláusulas pendientes de seguro de vida, plan médico, jornada de trabajo y bonificación. Las bonificaciones nunca han sido entregadas a los trabajadores en más de 15 aก̃os.

31-3-81:5 Sitracode.

Piden mayor seguridad para los trabajadores en la planta industrial. 
31-3-81:29 Sindicato Nacional de Transportistas Independientes de Carga.

Constitución legal. Reconocimiento a INESPRE. Niegan ser sindicato paralelo y critican a Fenatrado.

3-4-81:7 CGT.

Acusa gobierno en lucha maestros. Por un reajuste general de salarios. Libertad sindical. Llamado de unidad en torno al CNUS para enfrentar problemas de los trabajadores. Respaldo Sitracodal, telefónicos, Vulcano, Indhri y trabajadores del ingenio Porvenir. Por la reactivación y constitución del CNUS.

6-4-81:3 Sutrafado.

Niegan acusación que hacen el PCD y PTD al secretario general al vincularlo a un grupo de izquierda, lo que coincide con los planes que siempre ha tenido la empresa de destruir el sindicato.

11-4-81:17 SNTT.

Repudio atropello cuerpos castrenses. Por la vigencia de las libertades públicas. Por la firma del pacto colectivo. Solidaridad con otros sindicatos en lucha. Por la fundación de un CNUS fuerte.

14-4-81:29 Sitracode.

En asamblea trabajadores aprueban proyecto de pacto colectivo a ser presentado a la parte patronal.

15-4-81:29 Federación Nacional de Trabajadores de la Alimentación, Dulces y Bebidas (CGT).

Celebran segundo congreso. Aprueban línea general y programa. Conflictos pendientes: a) Cervecería Vegana: patronos han despedido impunemente 206 trabajadores y directiva del sindicato; b) Codal: violación al pacto colectivo y laudo arbitral y cancelación sindicalistas; c) Pepsi-Cola: despido de más de 125 trabajadores. Necesidad de coordinar plan de acción con todas las fuerzas sindicales para frenar ola de cancelaciones. 
Denuncian violaciones libertad sindical, pacto colectivo y laudo arbitral. Exigen pago bonificaciones completas a todos los trabajadores.

\section{1-5-81:25 UCGT.}

Invitación manifestación 1ㅇ de mayo: por la profundización del proceso institucional, respeto derechos sindicales, contra el alto costo de la vida, el incremento de la producción nacional, contra la penetración imperialista.

1-5-81:41 Fenatrado (CNTD).

Sobre conflicto con INESPRE sobre transporte carga.

1-5-81:40 Fensa.

Manifiesto 10 de mayo.

5-5-81:27 Sindicato de Trabajadores de la Cervecería Vegana. Empresa cancela más de 200 trabajadores por supuestos déficits, incluyendo parte de la directiva sindical. Respeto libertad sindical.

15-5-81:11 Sitracode.

Sobre ingreso personal nuevo que desconoce la CDE.

20-5-81:9 Sitrarodom.

Condenan represión policial contra el movimiento sindical, en específico contra dirigentes del CNUS.

25-5-81:3 Sutrafado.

Denuncian estado de represión contra la clase obrera. Denuncian propósitos de la empresa de reducir producción cuando se acerca la discusión de las cláusulas del pacto colectivo relacionadas con plan médico, pensión y jubilaciones.

26-5-81:8 Varios sindicatos del Ingenio Ozama.

Por ampliación del ingenio. 
28-5-81:8 Sitrarodom.

Critican gastos de alquileres de maquinarias innecesarios en la Rosario.

5-6-81:9 CGT.

Por rehabilitación minas de sal y yeso de Barahona.

9-6-81:3 UGTD.

Rechazan intento de Juan P. Gómez de llegar a la secretaría general en el segundo congreso por medios ilegales. Respaldo a la candidatura de Juan. P. Reyes.

9-6-81:5 Varios sindicatos del país y organizaciones de Bonao. Contra la amenaza de la Falconbridge de reducir horas de trabajo o despedir obreros.

10-6-81:3 UGTD.

Declaración de Juan P. Gómez: aunque ganamos abrumadoramente las elecciones para la dirección de la UGTD no ocuparemos cargos en virtud de los incidentes creados por los competidores Jacinto de los Santos y Juan P. Reyes al verse derrotados. Que se celebre nuevo congreso.

18-6-81:5 Sindicato Unido de Trabajadores del Central Romana.

Junta eleccionaria suspende votaciones ante hechos violentos que imposibilitan la continuación del proceso y determinaron la intervención policial.

26-6-81:9 Sutrafado.

Posición frente a amenazas de cancelaciones y reducción de salarios. Niegan supuesta crisis financiera de la empresa.

26-6-81:17 Sindicato Unido del Central Romana.

Apoyan medida junta eleccionaria. Condenan actos de violencia. Que se convoque a nuevas elecciones. 
9-7-81:7 Bloque de Sindicatos del Ingenio Río Haina.

Demandan cumplimiento pacto colectivo al CEA: cláusulas de igualdad de salarios, plan de viviendas, derecho a pensión, instalación de plantas eléctricas y suministro de agua potable en los bateyes.

30-7-81:7 Sutrafado.

Denuncian apresamiento de 5 miembros directivos del sindicato. Acusan Falconbridge de planes antiobreros.

30-7-81:13 Sitracaasd.

Después de dos años de lucha la asamblea decide: dar plazo de 30 días para que se discutan cláusulas pendientes y se firme pacto colectivo.

30-7-81:27 CNTD.

Refutan posiciones de empresarios y exhortan a aceptar cambios pacíficos.

4-8-81:3 Sitracode.

Demandan aumento salarios. Alerta ante planes de la administración de destruir sindicato.

21-8-81:5 Sitracode.

Denuncia intransigencia de la empresa sobre discusión pacto colectivo y rechaza intento de posponer discusión por un año. Rechaza violaciones de la policía y acusaciones de ser comunista.

\section{1-8-81:7 Sitrarodom.}

No a los gastos innecesarios de la empresa. Que se adquieran equipos pesados propios.

22-8-81:29 Sutrafado.

Preocupación ante situación movimiento obrero a nivel nacional y actitud empresarial y gubernamental. Contra las violaciones a las leyes laborales y embestida reaccionaria. Cese a la represión patronal 
28-8-81:17 Sindicato de Trabajadores de Nabisco-Tamara.

Solicitan discusión inmediata del pacto colectivo, cese de las cancelaciones en base a supuesto exceso de producción.

1-9-81:5 Federación Nacional de Sindicatos Azucareros (Fensa).

Demandan un conjunto de medidas al CEA y al gobierno para mejorar la situación económica de los ingenios y los trabajadores.

3-9-81:7 Comité Coordinador Provincial de Sindicatos Azucareros.

Demanda bono, condonación deuda, reposición cancelados, y condena decisión del CEA de cancelar el $10 \%$ de los trabajadores de los ingenios.

16-9-81:5 Sindicato Unido del Central Romana.

Informe de la gestión del consejo directivo.

19-9-81:5 Comité Coordinador de la lucha azucarera.

Pleno azucarero con la participación de la CGT, UGTD, CASC, CUT, CNTD y FENSA demandar bono de 90 días de salario para todos los trabajadores de factoría y campo, condonación prestamo año anterior, devolución descuento a los cancelados, cumplimiento pacto colectivo, respeto libertad sindical, cabal cumplimiento de la ley 45 de salario mínimo, y representación de los trabajadores en los consejos administrativos de los ingenios como lo dispone la ley 7 .

23-9-81:11 Sindicato de Billeteros y Quinieleros del Parque Independencia.

Contra amenaza de huelga de empleados de la lotería.

28-9-81:3 Sitracode.

En espera respuesta sobre pacto colectivo y otros compromisos con la empresa. 


\section{5-10-81:3 Sitracode.}

Esperan respuesta Presidente Guzmán en torno al pacto colectivo.

3-11-81:9 Bloque de Sindicatos del Ingenio Río Haina.

Contra respuesta del CEA a demanda pago bonificaciones. Que el CEA sostenga reunión con el Comité Coordinador Azucarero.

5-11-81:3 Comité Nacional de Lucha Azucarera.

Ante táctica dilatoria del CEA para dar respuesta a demanda bonificaciones se da plazo de 5 días para que el CEA comunique decisión.

11-11-81:5 Sitrarodom.

Exigen acuerdo sobre cláusula bonificación del pacto colectivo.

11-11-81:21 Sindicato de Choferes y Ayudantes y filial de Unachosin. División Transportación Hato Nuevo, CEA.

Demandan se cumplan cláusulas del pacto colectivo sobre dietas e igualdad de salarios para igual trabajo.

23-11-81:3 Sitracode.

Denuncian violación CDE al pacto colectivo. Amenaza movilizaciones y protesta en los centros de trabajo en demanda cumplimiento derechos.

2-12-81:19 Comité Nacional de Lucha Azucarera.

Contra intentos del CEA de no pagar bonificaciones de 45 días.

\section{4-12-81:9 Sitracode.}

Respuesta de lucha y movilización de trabajadores frente a violaciones y abuso de poder de la $\mathrm{CDE}$ en lucha por pacto colectivo.

4-12-81:29 Sitracaasd.

Después de más de tres afios de lucha se logra firmar pacto colectivo. 
22-12-81:7 Sinatraindrhi.

Rechazan cancelaciones y bajos salarios en el Indrhi. Por una mayor asignación en el presupuesto. Rechazan política de austeridad del FMI.

12-1-82:21 Sitracaasd.

Demandan se paguen salarios compensatorios y se suspendan planes de cancelación. Que se cumpla pacto colectivo y que no se descargue en los trabajadores la crisis económica de la institución.

12-1-82:24 Sindicato de Trabajadores de la Casa Central.

Denuncian violaciones, cancelaciones injustificadas, violación pago salario mínimo, incumplimiento seguro social y negativa de la empresa de negociar con el sindicato por considerarlo comunista.

14-1-82:7 Sitrarodom.

Ante dilatoria de la empresa en la entrega formal de viviendas para los trabajadores consignadas en el pacto colectivo se procede a ocuparlas.

15-1-82:11 Sitracaasd.

Rechazan injustas cancelaciones. La crisis económica no puede recaer en los trabajadores.

27-1-82:3 CGT.

En ocasión de la celebración de la VII Conferencia Interamericana de Ministros del Trabajo exponen situación de los obreros de la Falconbridge ante cancelaciones masivas.

30-1-82:24 Sutrafado.

Rechazan cancelaciones en la Falconbridge.

2-2-82:8 Sindicato de Trabajadores de la Oficina Nacional de Transporte Terrestre (ONATRATE)-Santiago.

Contra represión sindical y cancelaciones. Que se reconozca al sindicato. 
2-2-82:10 Comité de Choferes y Empleados Revolucionarios de Onatrate.

Que cese represión ante intento de organizarse. Demandan medidas económicas y sociales para beneficio de los trabajadores.

2-2-82:10 Fenatradube-CGT y Sindicato de Panaderos de las Matas de Farfán.

Reposición cancelados.

9-2-82:10 Sutrafado.

Repudio Falconbridge y gobierno perredeísta. Plan de lucha para la reposición de cancelados. Contra planes de la Falconbridge de reducir operaciones y cancelar empleados.

12-2-82:10 SNTT.

Alerta contra represión Codetel y planes de despidos masivos, lo que constituye una violación al pacto colectivo recientemente firmado después de un año de lucha.

26-3-82:5 Sitrarodom.

En demanda de eficaz servicio médico de acuerdo a lo establecido en el pacto colectivo.

26-3-82:13 Sindicatos de Billeteros y Quinieleros.

Rechazan planes y acusaciones de sindicatos minoritarios apoyados por los reformistas.

2-4-82:13 Sutrafado.

Rechazan represión contra el movimiento obrero.

2-4-82:13 Sindicato de Trabajadores del Hotel Santo Domingo e Hispaniola.

Demandan discusión y firma del pacto colectivo.

2-4-82:27 Sindicato de Trabajadores de Cementos Nacionales.

Que se firme pacto colectivo cuyo pre-proyecto se entregó a la empresa hace un año. 
26-4-82:5 Sindicato Autónomo de Trabajadores de la Tabacalera.

Exigen bonificación de tres meses y medio de salario. Llamado a la CGT y otras organizaciones para que brinden apoyo.

1-5-82:3 FENSA.

Manifiesto 1으 de mayo.

\section{COMUNICADOS EMPRESARIALES}

\section{Fuente: El Listín Diario}

16-9-78:24A AIRD, CPRD.

Critican activación de algunas centrales obreras por crear desconcierto e intranquilidad y contribuir a recesión económica. Reclaman intervención de las autoridades en la solución y terminación de los conflictos.

25-1-79:9 ACIS.

Expresan compromiso de contribuir al desarrollo del país.

24-2-79:9 AEIH.

Ante acontecimientos laborales reafirman necesidad de apego a las leyes y los procedimientos institucionales y obligación del Estado de garantizar estas prerrogativas.

26-2-79:1A CNHE (y organizaciones afiliadas).

Exhortación pública a los miembros del Congreso Nacional con motivo del inicio de la primera legislatura para que estudien con detenimiento todo cuanto se relaciona con el desenvolvimiento económico del país. Exponen decisión de participar activamente en los procesos legislativos. 
17-3-79:13B ACIS.

Recibe con beneplácito noticia rehabilitación muelle de Puerto Plata.

10-4-79:10 Asociación de Industriales de Muebles y Colchones. Aprueban medida del gobierno de prohibir algunas importaciones de productos fabricados en el país.

17-4-79:3 Asociación Nacional de Importadores.

Reclaman ser escuchados ante medidas prohibitivas de importación tomadas por el gobierno.

17-4-79:10A Asociación de Industrias de Zona Franca de Santiago Expresan inquietud por proyecto de ley que aumenta el salario mínimo a 125 pesos mensuales.

23-4-79:9A Asociación Nacional de Importadores.

Sobre medidas prohibición de importaciones tomadas por el gobierno y desacuerdo con la AIRD.

11-5-79:9 Asociación de Industriales de Muebles y Colchones.

Ante medida de prohibir importación de colchones, garantizan al gobierno calidad de los productos y un aumento en el uso de materia prima nacional.

4-6-79:19 Gulf + Western Corporation.

Refuta comunicado Sindicato Unido publicado en El Sol del 1 de junio con motivo de haberse suspendido laș negociaciones que venían realizándose para la concertación de un pacto colectivo.

20-7-79:2 CNHE (y organizaciones afiliadas)

Expresan preocupación al embajador de los Estados Unidos, Robert Yost, por política proteccionista de su país en perjuicio de las exportaciones de varios productos dominicanos.

11-8-79:9A METALDOM.

Exponen posición ante conflictos laborales surgidos 
en torno al registro del sindicato y el inicio de las discusiones sobre el pacto colectivo que llevó a una intervención policial.

13-8-79:12A AIRD, CPRD, AEIH, AIRD-RN.

Exponen posición ante conflictos laborales, y culpan de ello a centrales sindicales que luchan por controlar el movimiento obrero. Solicitan de parte de las autoridades un papel más efectivo en la mediación de los conflictos.

4-9-79:3 CNHE (y organizaciones afiliadas).

Con motivo del huracán David.

21-9-79:13 CNHE (y organizaciones afiliadas).

Constancia de no ser una institución al servicio de políticos ni de partidos.

29-9-79:9B CNHE (y organizaciones afiliadas).

Pronunciamiento en contra de alteración del orden establecido y apoyo a la constitucionalidad.

9-10-79:2 Asociación de Comerciantes de Mayoristas y Detallistas de Santiago.

Exponen conflicto en control de precios y motivo huelga realizada.

15-10-79:4 Asociación de Fabricantes de Productos Químicos, Cosméticos y Afines.

Establece recurso de apelación ante la Cámara de Cuentas debido a la aprobación de la solicitud de inversión extranjera por parte de la firma Johnson \& Johnson que autorizó el Directorio de Inversión Extranjera. Consideran desfavorable para el país la instalación de esta empresa debido a la capacidad ociosa instalada en el país.

20-10-79:13A AEIH.

Felicitan gobierno por adquisición de la Rosario Dominicana. 
6-11-79:17 Asociaciones Empresariales de Santiago y Puerto Plata.

Solicitan al Presidente Guzmán no desestime resolución del Directorio de Desarrollo Industrial que autoriza la instalación de una fábrica de envases de vidrio en Santiago.

6-11-79:12A Asociación Dominicana de Exportadores.

Considera de vital importancia se apruebe proyecto de Incentivo a las Exportaciones que cursa en las Cámaras.

6-12-79:4 Asociación de Fabricantes de Productos Químicos, Cosméticos y Afines.

Alarma ante declaraciones del Secretario de Industria y Comercio en el sentido de favorecer la instalación de la firma extranjera Johnson \& Johnson. Apelación al Presidente de la República para una decisión contraria.

10-12-79:9C Asociación de Industriales de Muebles y Colchones.

Se oponen a que la Secretaría de Educación compre pupitres en el extranjero.

12-12-79:9A Asociación de Fabricantes de Productos Químicos, Cosméticos y Afines.

Oposición a que se apruebe la instalación de la empresa extranjera Johnson \& Johnson.

21-12-79:11 ACIS.

Beneplácito por instrucciones del Presidente para rehabilitar muelle de Puerto Plata.

26-12-79:4 Asociación Dominicana de Productores de Ron.

Defienden empresas ante ataques de importadores de bebidas extranjeras por gravámenes.

16-1-80:22A ACIS

Exponen posición sobre ley 299 de Protección e Incentivo Industrial. Critican la parcialidad de la ley 
y del Directorio de Desarrollo Industrial por contribuir fundamentalmente al desarrollo de la industria en Santo Domingo.

18-1-80:1A AIRD, AIRD-RN, AEIH

Responden críticas de la ACIS sobre la ley 299 y enfatizan los resultados positivos de la ley para la industrialización del país.

23-1-80:7A ACIS.

Reafirman críticas planteadas sobre la ley 299 y su forma de implementación.

25-1-80:4A Cámara de Comercio, Agricultura e Industria de Puerto Plata.

Felicitan a la ACIS por pronunciamientos críticos sobre la ley 299.

26-1-80:2 Consejo Estatal del Azúcar.

Rechazan demandas obreras y consideran satisfechos reclamos del Comité Coordinador de Sindicatos Azucareros.

5-2-80:8 Asociación de Mayoristas de Provisiones de Santo Domingo.

Solicitan diálogo con el gobierno para tratar asuntos sobre comercialización de productos y la función de INESPRE. Piden se suspenda campaña de descrédito contra los comerciantes y el tráfico de influencia en las operaciones de INESPRE. Se quejan de no haber sido atendidos por las autoridades.

14-2-80:2A CPRD.

Invitación a Seminario Empresarial sobre Tribunales de Trabajo.

25-2-80:8A AIRD, AIRD-RN, AEIH.

Exponen problemas afectan industrias del cemento $y$ de muebles. 
21-3-80:7A Asociación de Mayoristas de Provisiones de Santo Domingo.

Exponen preocupación ante el sistema de distribución de azúcar refino, crema y de arroz implantado por INESPRE, desconociendo la existencia de canales naturales de distribución de estos productos a nivel nacional. Respaldan Federación de Comerciantes en los acuerdos aprobados en su asamblea.

1-4-80-13A Federación de Comerciantes Detallistas.

Defienden nuevo plan de distribución de INESPRE a través de cuotas por asociaciones, sean éstas de mayoristas o de detallistas, lo que evitará que unos pocos comerciantes mayoristas manejen a su antojo los productos.

14-4-80:13A Asociación de Fabricantes de Productos Químicos, Cósmeticos y Afines.

Alertan ante planes de la firma extranjera Johnson \& Johnson de comenzar instalaciones antes de que se conozca el fallo de la Cámara de Cuentas que actúa como Tribunal Superior Administrativo ante recurso puesto por la asociación.

1-5-80-9A CNHE (y organizaciones afiliadas).

Felicitación al trabajador con motivo del día del trabajo.

2-5-80:5 CNHE (y organizaciones afiliadas).

Reconocimiento de la Gulf + Western por donación tierras para la reforma agraria.

22-5-80:9A Asociación de Fabricantes de Productos Químicos, Cosméticos y Afines.

Refuta comunicado de la firma Johnson \& Johnson que presenta como positiva la instalación de esa empresa en el país.

3-6-80:13 Asociación Nacional de Detallistas de Gasolina.

Exponen posición ante crisis combustibles y las medidas adoptadas por el gobierno al respecto. 
6-6-80:3 CPRD, COCAI-DN, COCAI-STGO, AIRD, AIRD-RN, AEIH, ADHA.

Consideran inoportuna la discusión del proyecto de ley para la adopción de un 'Nuevo Código de Trabajo', ya que la aprobación de la pieza legislativa tal y como ha sido sometida afectaría en forma conflictiva el clima existente en las relaciones entre las empresas y sus trabajadores, debido principalmente a que minimiza el sector patronal. Solicitan se aplace discusión de este proyecto de ley.

11-6-80:2 Industrias Asociadas, C. por A. (INASCA).

Exponen motivo conflictos laborales en dicha empresa.

12-6-80:8 CNHE (y organizaciones afiliadas).

Oposición proyecto colegiación periodistas.

13-6-80:5 CNHE (y organizaciones afiliadas).

Apoyo discurso Luis A. Ginebra H. en Cena Unidad Empresarial.

13-8-80 CNHE (y organizaciones afiliadas).

Exponen preocupación por exposición de la $\mathrm{ADHA}$ en el sentido de que la finca de la familia Aguayo se pretende expropiar sin previo pago de su justo valor. Defensa de la propiedad privada.

23-8-80:8A Federación Nacional de Comerciantes Detallistas.

Apoyan acciones del gobierno para recuperar $38 \mathrm{mi}-$ llones que la Gulf + Western le debe al gobierno dominicano y el asentamiento de la finca Aguayo.

6-9-80:11 CNHE (y organizaciones afiliadas).

Felicitan al gobierno y a la Gulf + Western por la forma en que negociaron la firma del acuerdo sobre el pago de los 38 millones que la Gulf le adeuda al gobierno.

3-10-80:2 Asociación de Comerciantes de Santo Domingo.

Conflicto sobre cuota de azúcar que les corresponde y que INESPRE no ha entregado. 
12-11-80:5 Asociaciones Empresariales de Santiago: ACIS, AIRD-RN, COCAI-STGO.

Expresan preocupación por negativa del Senado de aprobar el préstamo de 90 millones para el CEA. Exhortan al Poder Ejecutivo y al Congreso Nacional a que conozca nuevamente el préstamo y que se apruebe el préstamo todavía en discusión de los 35 millones del Banco Mundial.

16-12-80:13A Asociación Dominicana de Pequeñas Industrias.

Aprueban propuesta $H$. De Camps de concertar préstamo de 7.5 millones para el desarrollo de la pequeก̆a y mediana empresa. Critican a FIDE por haber beneficiado al gran productor.

13-5-81:8 CNHE (y organizaciones afiliadas).

Que cese huelga médicos y que se busque solución al conflicto que le dio origen.

27-5-81:4 CNHE (y organizaciones afiliadas).

Rechaza proyecto aprobada por la Cámara de Diputados de impuesto al cigarrillo para satisfacer demandas médicos. Piden al Senado no aprobarlo.

4-7-11:14C Asociación Nacional de Agencias Distribuidoras de Vehículos.

Reconocen problemática económica del país, pero consideran que la prohibición de la importación de vehículos por un año es injusta ya que carga a un solo sector. Piden revisión del decreto No. 2496 y que se inicie el diálogo.

2-10-81:9 CNHE (y organizaciones afiliadas).

Constancia de su protesta ante el hecho de que las autoridades de los Estados Unidos han aplicado un impuesto proteccionista al azúcar dominicano.

10-10-81:11C Federación Dominicana de Comerciantes.

Sobre impuestos a las bebidas alcohólicas. 
11-10-81:5 CNHE (y organizaciones afiliadas).

Salutación al vice-presidente George Bush de los Estados Unidos.

2-12-81:2 CNHE (y organizaciones afiliadas).

Apoyo a la Asociación Nacional de Importadores en el sentido de que no se pague una prima superior al $30 \%$ y que se autorice a los bancos comerciales a funcionar en el mercado de divisas.

15-12-81:13 Asociación Nacional de Distribuidores de Vehículos y Efectos para el Hogar.

Piden la liberalización de la importación de vehículos. Señalan que la prima del dólar ha seguido subiendo y que ha recaído sobre ellos el sacrificio destinado a estabilizar ese mercado.

5-1-82:15 CNHE (y organizaciones afiliadas).

Que se suspenda totalmente la compra de divisas hasta que la prima del dólar baje al 30\%.

4-2-82:8 ACIS.

Exponen problemática monetaria del país y la necesidad de adoptar medidas para la solución de los problemas económicos.

4-2-82:5A Asociación Nacional de Importadores.

Aviso a todos los empresarios de no pagar más del $35 \%$ de prima y cautela en la compra de dólares para no presionar el mercado.

30-3-82:15 Asociación Dominicana de Distribuidores de Vehículos y Efectos para el Hogar.

Respaldo al gobierno por acatarse a los términos del decreto 2496 del 11 de junio de 1981, permitiendo la importación de vehículos a partir de junio.

12-5-82:16A AIRD-RN, ACIS, COCAI-STGO, Asociación para el Desarrollo de Santiago, UCMM, Obispado de la Diócesis de Santiago. 
Llamado a todos los candidatos políticos a mantener diálogo y actitud acorde con las normas civilizadas. Que la Junta Central Electoral y demás organismos del Estado cumplan su misión de garantizar las elecciones.

14-5-82:7A CNHE (y organizaciones afiliadas).

Apoyan solicitud de que se paralicen labores el 17 de mayo y hacen llamado a que se ejerza libremente el voto. 